\title{
SEGURIDAD Y MIGRACIÓN EN EL ESPACIO FRONTERIZO TABASCO-EL PETÉN
}

LUIS ALFREDO ARRIOLA VEGA*

RESUMEN: Este artículo aborda la relación entre dos temas complejos: migración y seguridad. Dicho nexo confronta aspectos tales como la soberanía del Estado nacional frente al derecho a la libre movilidad humana; la línea tenue que puede plantear el dilema de lo jurídicamente legal versus lo socialmente legítimo; la defensa de una particular forma de concebir la seguridad de cara a reales y potenciales amenazas, por ejemplo una pandemia o una ataque terrorista. La descripción cualitativa de actividades consideradas ilícitas por el Estado, entre ellas el flujo de extranjeros con estatus migratorio irregular que transitan por la colindancia entre Tabasco (México) y El Petén (Guatemala), ofrece una primera radiografía de la conexión migración-seguridad en su dimensión local, pero sin perder de vista su alcance internacional. La proyección global de este intricado vínculo plantea la ineludible necesidad de concebir nuevos esquemas de seguridad orientados a una gestión democrática del fenómeno migratorio.

PALABRAS CLAVE: migración, seguridad, frontera México-Guatemala, actividades ilegales, colindancia.

ABSTRACT: This paper analyzes the relationship between the complex subjects of migration and security, which encompasses issues such as national sovereignty versus free human mobility; what is judicially legal versus what is socially legitimate, and the defense of particular notions of security when faced by both real and potential threats, such as a pandemic or a terrorist attack. A qualitative description of the flow of undocumented migrants across the region of Tabasco (Mexico) and El Petén (Guatemala), an activity labeled as illicit by the state, provides an initial look into the relationship between migration and security on a local level. However, the ultimately global presence of this process requires new ways of conceiving security, ways that can ensure a democratic management of the migration phenomenon.

KEYwORDs: migration, security, Mexico-Guatemala border, illegal activities, boundary.

* El Colegio de la Frontera Sur, Unidad Campeche, Línea de Migraciones en la Frontera Sur de México, Investigador, correo electrónico: larriola@ecosur.mx 


\section{INTRODUCCIÓN ${ }^{1}$}

E

ste es un primer acercamiento a un tema de muchas aristas. Es complejo porque toca y confronta aspectos tales como la soberanía del estado nacional frente al derecho a la libre movilidad humana; la línea tenue que puede plantear el dilema de lo jurídicamente legal versus lo socialmente legítimo; la defensa de una particular forma de concebir la seguridad de cara a reales y potenciales riesgos, bien sea una pandemia o una amenaza terrorista. Estas dicotomías y tensiones están vivas en la franja colindante entre Balancán y Tenosique, municipios de Tabasco, México, con San Andrés y La Libertad, municipios de El Petén, Guatemala.

El artículo se divide en tres partes. La primera aborda el paradigma de seguridad dominante en contraste con otro, emergente y alternativo. En la segunda parte la discusión se traslada al posicionamiento de problemas relativos a la seguridad en el marco de una frontera internacional, a manera de encuadrar conceptualmente lo que acontece en la adyacencia entre Tabasco y El Petén. La siguiente sección describe actividades no reguladas existentes en esta zona fronteriza que - desde la visión estatal- plantean riesgos potenciales a la seguridad pero que deben ser entendidas en su contexto socio-económico para analizarlas en su justa dimensión; parte de este análisis pasa por reconocer que esas actividades trascienden lo meramente local, es decir que adquieren alcance regional y mundial.

Argumento en la parte final que el flujo migratorio en tránsito por la frontera México-Guatemala no representa un riesgo a la seguridad de México, o para el caso Guatemala, debido a sus características, dimensiones y dinámica actual. Desde una perspectiva multidimensional de la seguridad los migrantes que transitan por territorio mexicano más bien son víctimas de las circunstancias imperantes. En ese sentido, el reto para los aparatos estatales estriba en impulsar una política de gobernabilidad migratoria democrática (Villafuerte y García, 2007) tendiente a una gestión positiva de la complicada relación entre seguridad, migración y frontera.

\section{CONCEPTUALIZACIÓN DE SEGURIDAD IN FLUX}

El tema de seguridad en la frontera ha sido tradicionalmente abordado desde una posición estado-céntrica (Liotta, 2002), la cual se fundamenta en la defensa de la

\footnotetext{
1 El artículo constituye un avance de resultados obtenidos dentro del proyecto «Efectos sociales y económicos derivados de fenómenos migratorios en la frontera Balancán-Tenosique/Petén». La investigación está bajo la responsabilidad del autor del texto y cuenta con financiamiento del gobierno del estado de Tabasco y el Consejo Nacional de Ciencia y Tecnología (Fondos Mixtos, Clave TAB-2007-09-75064).
} 
integridad territorial del estado, la soberanía, y otros cuestiones de esta índole, ${ }^{2}$ generalmente a cargo de uno o varios aparatos del estado. La desaparición de un mundo bi-polar posterior a la caída del muro de Berlín en 1989, la aceleración de procesos globalizantes y, ciertamente, los acontecimientos acaecidos en las torres gemelas del Wall Street Center en septiembre de 2001 han desplazado el esquema de seguridad de la guerra fría hacia paradigmas que, o bien refuerzan los esquemas tradicionales, o bien plantean propuestas alternativas. Todo parece indicar que, en el caso de México, el país ha seguido la primera opción al participar en el programa Alianza para la Seguridad y Prosperidad de América del Norte (ASPAN), al implementar el monitoreo de viajeros con tecnología informática de punta y al incorporar al Instituto Nacional de Migración (INM) al sistema de Seguridad Nacional de México (Artola, 2006), acciones enmarcadas en un renovado proyecto de seguridad nacional. En ese tenor y desde una perspectiva geopolítica continental, hay autores (Andreas, 2003) que consideran que las políticas de seguridad adoptadas por el estado mexicano posterior a septiembre 2001 proveen a Estados Unidos con una zona de amortiguamiento de facto para la aplicación y cumplimiento de leyes afines a la política de seguridad estadounidense, la cual encuentra en la frontera sur mexicana un punto neurálgico.

Dentro de esa nueva racionalidad de seguridad el orbe constituye un complejo entramado indiviso de tal suerte que cualquier amenaza local, regional o nacional puede transformarse en un peligro mundial no precisamente controlable en forma coercitiva, ni por la acción individual o conjunta de países poderosos (Dillon, 2005). La situación del virus A1H1N encarna un ejemplo contemporáneo. La contingencia sanitaria derivada de la aparición de este virus paralizó a México durante varias semanas en 2009, se extendió al resto del planeta muy rápidamente y aun al momento de escribir estas líneas el virus parece no detenerse. Bajo esta lógica, escenarios como el anterior serán cada vez más recurrentes y dan sentido y contenido a un término que va ganando cada vez más terreno en la discusión: la «securitización» de supuestas y reales amenazas. ${ }^{3}$ Si bien antes existía una clara distinción -o por lo menos consenso generalizado- entre amenazas internas y externas, la situación actual ha cambiado y ambas se entremezclan para producir lo que Juan Artola se ha dado en llamar amenazas «intermésticas» (Artola, 2006: 193). Artola no define con precisión el concepto ni abunda en sus características, pero lo interméstico se asume en este trabajo como aquella condición en la cual amenazas y riesgos operan simultáneamente desde múltiples escalas y planos, a saber, de mayor a menor, de abajo hacia arriba, de adentro hacia fuera y viceversa.

\footnotetext{
El término seguridad nacional nos remite, precisamente, a esa visión militar, de inteligencia, de control y vigilancia que dominó la concepción de la seguridad hasta tiempo reciente. Es a partir de esta doctrina de seguridad de antaño que regímenes autoritarios, militaristas y/o represivos encontraron su sentido y razón de ser para el control y manejo de amenazas externas e internas -como sucedió por mucho tiempo en Latinoamérica-.

3 Sobre una visión crítica de la securitización de enfermedades infecciosas ver Davies, 2008.
} 
Los peligros y amenazas intermésticas se asocian con una noción alternativa a la visión estado-céntrica y hegemónica de seguridad denominada seguridad humana. ${ }^{4}$ Desde esta perspectiva el énfasis de la seguridad se sitúa en el ser humano, bien sea como individuo o como grupo. Seguridad humana empezó a ser utilizado en el discurso académico latinoamericano desde inicios de la década de la década de 1990. Por ejemplo, Jorge Nef, politólogo chileno, promulgaba ya en 1991 la necesidad de reducir riesgos cuya envergadura eventual pudiera tener alcance mundial como una forma de contribuir a reducir la inseguridad, verbigracia, una crisis local que se desborda y afecta a todo el globo (Nef, 1991). Seguridad humana concierne, decía Nef, al grueso de la población no sólo a territorios, regímenes, o élites o bloques de países en particular. ${ }^{5}$ Al poco tiempo, en 1994, el informe sobre Desarrollo Humano del Programa de Naciones Unidas para el Desarrollo incluiría dos capítulos en los cuales esboza una ruta crítica para un nuevo paradigma internacional cuya piedra angular es, justamente, la seguridad humana. Allí se reconoce que las amenazas a la seguridad ya no son individuales, locales o nacionales, si no de alcance internacional. Las drogas, el SIDA, el terrorismo, la contaminación, la proliferación nuclear, la crisis alimentaria constituyen algunas de esas amenazas (Un, Development Program, 1994: 2). ${ }^{6}$ Así pues, la noción de seguridad humana adquiere un contenido «...holístic[o], interrelacionad[o] y multidimensional». (Nef, 1995: 10). Más adelante elaboraré el argumento en pro de integrar esta perspectiva a nuevos planes de seguridad como una forma de mediatizar y equilibrar el enfoque dominante y con particular atención al tema de la migración que transita por la frontera sur de México.?

\footnotetext{
${ }_{4}^{4}$ Para efectos de este artículo considero una variante del término a la así llamada seguridad democrática aunque estoy consciente que, en estricto sentido, esta acepción pueden concebirse de otra manera.

${ }_{5}^{5}$ Estas ideas fueron desarrolladas más ampliamente en Nef, 1999.

- Según Peter Liotta constituyen amenazas aquellas que son claramente identificables, están presentes y requieren respuestas comprensibles, por ejemplo, el uso de la fuerza militar frente a agresiones externas (Liotta, 2002: 478, 479). Se concibe a las vulnerabilidades como indicadores no tan nítidamente identificables, con interdependencia entre temas articulados, pero sin claridad en cuanto a las responsabilidades y respuestas correctas que deban dárseles. Las migraciones, los peligros epidemiológicos, los desastres naturales, el narcotráfico son vulnerabilidades que pueden convertirse en amenazas pero para las cuales no existe una respuesta fácil o clara en términos de seguridad (Liotta, 2002: 479). Como suele suceder con paradigmas emergentes también ya se han expresado puntos de vista contrarios a esta nueva forma de concebir la seguridad (Ver, por ejemplo, Bellamy y MacDonald, 2002; Ewan, 2007), incluso llegándose a cuestionar la existencia de una verdadera correspondencia entre lo que se promulga en el discurso y lo que sucede en la práctica (Ryerson, 2008).

7 La existencia de distintas conceptualizaciones y posiciones indica una falta de consenso sobre la seguridad a muchos niveles, ciertamente en el concurso internacional de naciones. En la práctica lo que significa e implica el tema de seguridad difiere substancialmente entre países desarrollados y aquellos en desarrollo. Para algunas naciones europeas y Estados Unidos, la principal prioridad de seguridad es el terrorismo. En los países más pobres la seguridad pasa primordialmente por la capacidad de ofrecer a la población agua potable, vivienda, salud, educación (Fraser, 2006: 3). El debate es amplio, como lo demuestra la creciente literatura sobre el mismo. Véase Buzan et al., 1998; Tulchin, 2005; McCormack, 2008.
} 
La existencia de amenazas externas, internas e intermésticas abre la posibilidad de que en determinadas situaciones surjan escenarios en los cuales sea necesario implementar esquemas concurrentes de seguridad humana y seguridad estado-céntrica, es decir, la aplicación de un enfoque multidimensional. ${ }^{8} \mathrm{Si}$ una amenaza o riesgo conlleva potenciales repercusiones a diversas escalas y planos su solución tendrá que atenderse desde una perspectiva multilateral: los problemas derivados del consumo de drogas son un asunto de índole interno y de salud y seguridad pública en cada país, mas la envergadura y naturaleza de su comercialización conlleva una dimensión de seguridad, y por tanto un tratamiento, de orden internacional. Pero antes de pasar a la discusión de esos riesgos y amenazas de seguridad que se presentan en forma de actividades no reguladas en el límite fronterizo El Petén-Tabasco es importante definir y describir la esfera en la que acontecen esas actividades.

\section{LA FRONTERA INTERNACIONAL COMO ÁMBITO DE RIESGOS Y AMENAZAS A LA SEGURIDAD ESTADO-CÉNTRICA}

Parto en este trabajo de que cada frontera entre dos o más países constituye un límite geopolítico caracterizado, simultáneamente, como institución y proceso. Para Malcom Anderson la representación institucional de una frontera se rige por principios territoriales y se establece con base a consideraciones políticas (Anderson, 1996: 1). En su manifestación como proceso las fronteras cumplen varios papeles, entre ellos constituir instrumentos activos de la política estatal y, en general, mas no siempre, como demarcaciones de una identidad nacional (Castillo, 2002: 30). Vargas (1993), considera que las fronteras representan localidades de transición entre las territorialidades de dos estados-nacionales, idea con la cual concuerdo plenamente. Siguiendo lo postulado por Wilson y Donnan (1998: 9), planteo tres elementos que se combinan para definir la frontera: la línea material que separa a los estados nacionales, las estructuras que definen esa línea (constituidos por instituciones y personas) y la franja territorial existente a lo largo y a través de esa línea.

Lo que sí queda claro es que una frontera estatal es producto de su contexto económico particular y de la interacción de las fuerzas políticas dominantes a distintos niveles, rara vez engendrada como reflejo de los intereses de la población que reside en su rededor (De Vos, 1993: 14). Es el caso de la delimitación entre El Petén y Tabasco, negociada en las distantes capitales de México y Guatemala, respectivamente, y trazada a la medida de los intereses de la época, es decir para

8 Según Jorge Rodríguez B. (2006) el término «seguridad multidimensional» antecede al de seguridad humana, habiendo sido acuñado en el seno de la Comunidad de Estados del Caribe (CARICOM). 
favorecer a empresas madereras que dominaban la economía regional al final del siglo diecinueve. ${ }^{9}$

Aunque la división política entre México y Guatemala se definió formalmente a partir de 1882 su consolidación como referente estatal es muy reciente. Con esto quiero decir que la presencia efectiva y permanente del estado es asunto pendiente en el caso petenero y un desarrollo bastante nuevo, no más de medio siglo, en el caso tabasqueño. Lo anterior facilita que a lo largo de toda la zona fronteriza exista libre tránsito de bienes y personas, abriendo la puerta a diversas actividades consideradas irregulares. ${ }^{10}$ Esta amplia porosidad del espacio fronterizo binacional hace necesaria una reflexión sobre las implicaciones de seguridad en un lugar que es tierra de nadie... y de todos. Hay por lo menos tres consideraciones a tomar en cuenta para entender las limitaciones del abordaje de seguridad estado-céntrico en el tratamiento de amenazas y riesgos en este espacio fronterizo, incluido el tema de la transmigración.

Una de esas consideraciones está ligada al campo del derecho internacional. El hecho de que las leyes difieran de un país a otro, o que se aplican de manera desemejante en cada país, puede favorecer las actividades ilícitas transfronterizas. Un contrabandista sabe que al pasar al otro lado de la frontera la ley del país de donde sale no puede alcanzarlo, al menos no tan fácil y rápidamente (Naím, 2005: 274). De manera similar, lo que se prohíbe, regula o controla en un país, quizás difiera en mayor o menor medida en el otro. Para el caso que aquí nos ocupa la disparidad substancial en las normatividades y controles en torno a la posesión de armas en manos de civiles para Guatemala y México es un ejemplo a considerar. Los habitantes mexicanos de la frontera ven con asombro y no poca preocupación que a los guatemaltecos se les permite la portación «laxa» de armas de fuego; aunado a un clima de violencia, impunidad y una creciente ingobernabilidad en Guatemala, el espacio fronterizo es terreno fértil para hechos violentos, crímenes y otras arbitrariedades, en muchos casos dirigidas a los migrantes que pasan por la zona en su camino a Estados Unidos.

Una segunda consideración es de orden social. Para los habitantes fronterizos involucrados en actividades irregulares éstas constituyen oportunidades para "ganarse la vida»: las actividades consideradas ilícitas en el espacio fronterizo han sido aceptadas culturalmente desde mucho tiempo atrás, incluso antes de que el estado-nación pusiera atención a estos confines. Entendidas en tanto formas de vida para la sobrevivencia en condiciones adversas, y hasta hostiles, las actividades que riñen con la ley adquieren así su legitimidad social por costumbre y aprobación colectiva. Lo cierto es que algunas de ellas muestran una continuidad histórica de varios siglos, evidenciando que la demarcación internacional entre los dos países ha sido más simbólica que real. En el pasado reciente un habitante local

9 Para una discusión ampliada de la frontera sur como región véase Castillo, 2002, pg. 29-36 y Castillo, Touissant y Vázquez, 2006, pp. 15-23.

${ }^{10}$ También denominadas ilegales, ilícitas, subterráneas. Ver la tercera parte de este artículo. 
pudo combinar la caza ilegal de lagartos (en Guatemala) con el desmonte de la selva (en México), más adelante dedicar parte del tiempo al corte no autorizado de madera (en Petén) con el cultivo de chile (en Tabasco), y para el momento actual criar ganado, por un lado, y ofrecer alimentación y hospedaje a migrantes de paso, por el otro (a ambos lados de la frontera). Como afirma Moisés Naím toda actividad ilícita se mantiene y prospera porque deja grandes ganancias, no por consideraciones de orden moral (Naím, 2005: 239). Eso mismo me dio a entender un informante local en una charla franca y abierta sobre los migrantes. Parafraseo a Paco Roca (seudónimo), de avanzada edad, habitante de un ejido fronterizo en Balancán, y cuya vivienda está a la vera del camino por donde transitan casi a diario camionetas tipo pick up con migrantes: Desde su perspectiva ofrecer transporte a estos transeúntes no es un oficio inherentemente anómalo porque se está prestando un servicio. Dijo: «se cubre una necesidad». No obstante, Roca si reconoció que jurídicamente era algo incorrecto (Comunicación personal, abril 2009).

Aunque una parte de los habitantes fronterizos se ha dedicado simultáneamente a actividades regulares e irregulares no debe pensarse que esto ha existido siempre. Quien estuvo involucrado en actos ilícitos en el pasado puede que no lo haga más en la actualidad. El mismo Roca había cortado palma xate ${ }^{11}$ en el vecino Petén, unos 20 años atrás, para poder sostenerse en un momento en el cual una terrible sequía azotaba la región. En lo tocante al fenómeno migratorio, la propia dinámica de los flujos y la respectiva respuesta del estado central determinan los alcances de oportunidad para hacer dinero o no. Cuando el ejército guatemalteco, o el inm en México, colocan un retén o un puesto de control en x punto de cruce clandestino, la trayectoria y el paraje de ingreso a Tabasco se moverán a un punto Y más al norte o más al sur de la «raya». Si el mes pasado el negocio era bueno en Cacaote (nombre ficticio) en el siguiente «la cosecha de mojados» puede favorecer a Jolepe.

Un tercer elemento que hace complejas las acciones del estado en términos de seguridad y migración en la frontera es la existencia de localidades con una estrecha relación en la colindancia internacional. Aquí retomo, aunque de una manera diferente, una analogía enunciada por Manuel A. Castillo al referirse a espacios de intenso contacto en la frontera México-EUA, concretamente las áreas metropolitanas contiguas como Tijuana-San Diego, Brownsville-Matamoros (Castillo, 2005: 54). Aunque no existen esas "díadas urbanas» en la frontera Tabasco-El Petén, entre otras razones, debido a que la densidad de población es menor, y el nivel de urbanización bajo (Castillo 2005: 54), si quiero argumentar aquí que los puntos de contacto agudo en esta circunscripción tienen otra índole y escala: son rurales, de modesta dimensión, con escasa visibilidad y definitivamente signados por las actividades subterráneas. El mercado informal en El Ceibo (ver abajo), la

${ }_{11}$ Planta ornamental de exportación que se extrae de zonas de bosque que no han sido transformados para la agricultura o la ganadería. 
migración de paso en situación irregular, el tráfico de drogas, incluso en algunos momentos el trasiego de armas, encarnan las fuerzas y procesos que dan vida a estrechos vínculos en estos intersticios fronterizos globalizados. Uso el término intersticio a propósito ya que desde la visión estado-céntrica se trata de hendiduras, grietas que socavan precisamente la autoridad -simbólica y real- del aparato estatal, cuestionando una particular forma de ver la seguridad desde arriba. Cito nuevamente a Manuel A. Castillo para ilustrar mejor el punto:

En ese sentido, se genera una tensión entre los llamados «intereses nacionales» y las actividades locales, mismas que muchas veces no reconocen ni aceptan de buen grado los límites impuestos desde los centros de poder. Resulta difícil para los residentes fronterizos percibir, y más aun aceptar, lo que en el Centro se identifica como amenazas a la soberanía y la seguridad nacional... (Castillo, 2005: 56).

Las acciones de distintos cuerpos del orden que realizan controles policiacos y migratorios bajo la consigna de atacar el tráfico de migrantes en nombre de la seguridad nacional pueden crear malestar e inseguridad entre los habitantes fronterizos (Castillo, 2005: 58), situación que es exacerbada por hechos de corrupción y una escasa, o nula, auditoría social sobre el quehacer de las autoridades. Es en respuesta a ese malestar que las actividades subterráneas, incluyendo los negocios ligados a la migración de tránsito, son asumidas por algunos sectores de la población como prácticas contra-hegemónicas, es decir contestatarias al estado y a sus mecanismos de control. ${ }^{12}$ Bajo las condiciones actuales, tal premisa encuentra referentes concretos en coordenadas específicas de la frontera El Petén-Tabasco donde la agenda estatal no corresponde con la agenda de los actores locales debido a que actividades extra-estatales de carácter internacional «...debilitan al estado-nación al restringir su habilidad para contrarrestar el ataque de las redes mundiales que socavan la economía, corrompen a sus políticos y subvierten a sus instituciones». (Naím, 2005: 8) (Traducción libre). La siguiente sección discute con cierto detalle el alcance y naturaleza de esas actividades en la zona fronteriza para luego abordar el por qué es pertinente integrar una perspectiva de seguridad humana al tratamiento de estos temas.

\section{DE LAS ACTIVIDADES SUBTERRÁNEAS EN EL ESPACIO FRONTERIZO TABASCO-EL PETÉN}

Las situaciones que no se ajustan a lo políticamente regulado (the politically normative) (Navaro-Yashin, 2003), a aquello que conlleva un estatus jurídico marcado por una relación con el estado (De Genova, 2002) son denominadas actividades y

${ }^{12}$ Esta idea fue planteada previamente por Staud (1998) al referirse a la situación prevaleciente en determinados puntos de la frontera México-Estados Unidos. 
actos ilícitos ${ }^{13}$ transfronterizos. Vinculado a la dicotomía legal-ilega ${ }^{14}$ está el tema de lo legítimo e ilegítimo. Cuando estas prácticas son de uso extenso y amplia aceptación social, su legitimidad cultural sobrepasa o está por encima de las definiciones jurídicas. En referencia a situaciones de la vida real Josiah Heyman y Alan Smart sostienen que:

...la legitimidad siempre recae en la ley y nunca con el crimen o la ilegalidad. No obstante, los mercados negros, el soborno, la migración ilegal, la protección brindada por mafiosos, etc., adquieren [una] considerable legitimidad real, a veces por parte de ciertos segmentos de la sociedad, a veces por parte de la sociedad en su conjunto (Heyman y Smart, 1999: 19). (Traducción libre).

Tomando como punto de partida las consideraciones anteriores, la definición operativa de actividades subterráneas utilizada aquí asume que: 1o) se conciben desde el punto de vista del estado, no desde la visión de los habitantes locales; 2o) en ellas están involucrados tanto mexicanos como guatemaltecos; 3o) generalmente, más no siempre, se realizan en ambos sentidos, y 4o) sus repercusiones trascienden el espacio fronterizo. Nótese que la tercera y cuarta características pueden conferir a esas actividades un carácter interméstico. Esta definición también incluye determinados ilícitos coyunturales que se registran en la franja de la colindancia internacional.

Dentro de las actividades subterráneas de antaño se pueden mencionar el trasiego de piezas arqueológicas, chicle, fauna, ganado y madera, entre otras (Schwartz, 1990). De todas ellas las que aún persisten son la extracción ilícita de maderas finas y el contrabando de ganado. La madera sale actualmente de Guatemala hacia México (vía Campeche); el movimiento transfronterizo de reses está presente en la colindancia Tabasco-El Petén y opera habitualmente en función de los precios de la carne y la tasa de vigente entre el peso y el quetzal. ${ }^{15}$ También

${ }^{13}$ Existe una creciente literatura sobre el tema, en el cual las prácticas de lo ilegal (Heyman, 1999) son igualmente denominadas como extra-legales, no-jurídicas, informales o extra-estatales. Véase entre otros: Heyman y Smart, 1999; Friman y Andreas, 1999; Nordstrom, 2001, Schendel y Abraham, 2005. Estoy consciente que otros autores, como Moisés Naím (2005), consideran que las prácticas extra-legales han dejado de ser subterráneas. No obstante, este mismo autor afirma que los contrabandistas son difíciles de identificar porque ellos se esconden a plena vista (Naím, 2005: 65).

${ }^{14}$ Nicholas de Genova captura con precisión la distinción estado-céntrica de lo legal e ilegal de la siguiente manera:

Es útil considerar aquí una distinción entre aquello que simplemente se sale de cualquier precisión legal prohibitiva y por tanto está más allá del ámbito de la ley, por un lado, y aquello que se constituye como ilegal, por el otro (Cf. Heyman y Smart, 1999: 1). La ley define los parámetros de sus propias operaciones, engendrando las condiciones de posibilidades para prácticas «legales» e «ilegales.» Las «ilegalidades» se constituyen y controlan inflexiblemente por la ley -en forma directa y explícita-, de un modo que se supone es más o menos definitivo (si bien no exento de múltiples ambigüedades e indeterminaciones, siempre manipulable en la práctica) y con un grado considerable de deliberación calculada. (De Genova, 2002: 424) (Traducción libre).

${ }^{15} \mathrm{La}$ entrada en vigencia del TLCAN también influyó en este flujo debido a que la exportación de carne estadounidense a México, a partir de 2002, ocasionó problemas para la industria ganadera 
han surgido y decaído actividades ilícitas transfronterizas espontáneas, y de índole más circunstancial. Fue el caso reciente, por ejemplo, de la salida de gasolina hacia Guatemala debido a la diferencia significativa registrada en el precio de los hidrocarburos y que favorecía al combustible mexicano. ${ }^{16}$

El surgimiento de amenazas en diversos puntos de la colindancia México-Guatemala es un fenómeno relativamente reciente y que está estrechamente ligado a actividades subterráneas. Nunca como hoy se han sentido con mayor fuerza las repercusiones que se derivan de esas actividades y, lo más importante, que trascienden, como ya se dijo, la esfera de lo local. Es precisamente su estrecha relación con procesos derivados o vinculados a la mundialización lo que les confiere un nuevo carácter y una renovada urgencia. Para evidenciar la naturaleza y dinámica de las actividades subterráneas presentes en la zona fronteriza que comparten Tabasco y El Petén primero describo el tráfico de narcóticos, luego el comercio no regulado en un punto fronterizo específico de esa franja para, en tercer lugar, abordar el tema de la migración en tránsito hacia Estados Unidos.

\section{NARCO-ECONOMÍA}

El narcotráfico constituye una de las actividades ilícitas internacionales que ha dejado su huella en el espacio fronterizo de interés, ejemplo de un proceso de escala multi y transnacional. Si aceptamos lo postulado por Naím (2005: 19), a saber, que el crecimiento del comercio mundial debido a la globalización también abrió las puertas para el avance del comercio ilícito internacional, ${ }^{17}$ el desarrollo de los mercados de consumo de estupefacientes en países de destino y su consiguiente incremento en toda la cadena de producción y distribución de narcóticos a nivel mundial es parte del «lado clandestino» de la globalización (Andreas, 2003). Es en ese gran telón de fondo que los cárteles iniciaron operaciones en territorio guatemalteco desde por lo menos fines de la década de 1990, como parte del corre-

de áreas de gran producción, como Tabasco. Desde esta entidad se enviaban reses al norte del país pero los productores tabasqueños no pudieron competir con los precios de la carne importada desde Estados Unidos.

${ }^{16}$ Los medios de prensa guatemaltecos publican con frecuencia sobre este tema. Ver la nota aparecida en el diario guatemalteco Prensa Libre, edición electrónica, del 21 de julio de 2009: "Gasolina que venden de contrabando es más barata» http://www.prensalibre.com/pl/2009/julio/21/328809. html, portal visitado el 11 de noviembre, 2009. En julio de 2008 presencié como un mexicanoguatemalteco residente en un poblado guatemalteco fronterizo de La Libertad se embarcaba una lancha con varios toneles de combustible para importarlo furtivamente a territorio guatemalteco vía el Río San Pedro.

${ }^{17}$ A continuación algunas cifras que Moisés Naím presenta para ilustrar el volumen del problema en las fronteras de EUA: En 2004 el negocio en torno a la mariguana alcanzó los 7 billones de dólares anuales en el límite Canadá-EUA, según autoridades canadienses (Naím, 2005: 71). Un kilo de cocaína alcanzaba un precio que variable entre los $\$ 12,000$ y $\$ 35,000$ después de cruzar la frontera México-EUA. (Naím, 2005: 77). 
dor intercontinental americano que conecta los centros de producción con los de consumo (Benítez, 2009: 2). La proximidad de Petén a México y la porosidad de la frontera binacional hacen del lugar una localidad estratégica para actividades ligadas a la narco-economía; es así que en la actualidad persiste el movimiento de drogas, fenómeno que no ha pasado desapercibido para conocedores de la zona (De Vos, 2005). En tiempo reciente ha existido trasbordo de cargamentos de cocaína en dos o tres puntos fronterizos y siembra de marihuana en territorio petenero (datos obtenidos en campo).

El surgimiento de asentamientos humanos en territorio guatemalteco, a lo largo de la franja fronteriza, durante las últimas tres décadas ${ }^{18}$ también ha contribuido directa e indirectamente al florecimiento del comercio transfronterizo de narcóticos. Algunas comunidades guatemaltecas adyacentes a México fungen - de manera discrecional- como enclaves logísticos para esta actividad subterránea contemporánea. Al igual que con otros ilícitos, los habitantes locales guardan gran hermetismo hacia fuera sobre lo que acontece localmente pero hacia dentro es de conocimiento público quien está involucrado, como se lleva a cabo toda la operación y donde se encuentra ubicado el área de cultivo, almacenaje o procesamiento, según sea el caso. Aún falta explorar y conocer con más detenimiento la supuesta conexión entre la migración y los grupos que trafican con drogas. Si bien algunas autores (véase Benítez, 2009; Martínez, 2009) afirman o dejan entrever la existencia de dicho vínculo, ésta (falsa) amenaza es de baja intensidad en la zona de estudio, a partir de lo que he podido observar. La falta de pruebas contundentes sobre el nexo directo entre ambos fenómenos es un asunto delicado porque puede dar lugar a un discurso manipulado de la seguridad humana, como afirma Maggie Ibrahim (ver nota al pie de página 26).

\section{EL MERCADO INFORMAL EN EL CEIBO}

La migración, el narcotráfico y el contrabando hacen que ciertos puntos geográficos de la frontera México-Guatemala semejen, en el momento actual, réplicas a pequeña escala de «hoyos negros geopolíticos», ${ }^{19}$ espacios donde reina la ingobernabilidad, en los cuales las pautas que rigen el buen orden en condiciones normales simplemente no existen. En esos ámbitos prosperan actividades ilícitas con impactos extralocales (Naím, 2005: 265).

El Ceibo (La Libertad, El Petén), adyacente a Sueño de Oro (Tenosique, Tabasco) ilustra -al menos parcialmente- la imagen del hoyo negro geopolítico. El sur-

\footnotetext{
${ }_{18}$ Los estudios sobre el desarrollo de estas comunidades constituye una asignatura pendiente, tarea que arrojaría muchas luces sobre los temas aquí esbozados.

${ }^{19}$ El concepto hace referencia, concretamente, a los estados fallidos y a los estados granujas o bravucones (rogue nations). (Naím, 2005: 62).
} 
gimiento de un mercado no regulado en 2000, en territorio guatemalteco, ha evolucionado rápidamente hacia la expansión de una comunidad empresarial. ${ }^{20} \mathrm{El}$ atractivo de El Ceibo como plaza de mercado para una ávida clientela mexicana es la disponibilidad de mercancía barata, principalmente de origen chino. Además, se rumora que también es posible adquirir armas. Esa mercancía ha ingresado en muchos casos a Guatemala, irónicamente, como contrabando. Los compradores mexicanos llegan de muy lejos, según pude comprobar por las placas de los vehículos que cada fin de semana abarrotan el lugar. Por su ubicación estratégica y el crecimiento experimentado últimamente la localidad se ha convertido en lugar de paso importante para los migrantes que van a EUA, si bien ese flujo ya acontecía desde por lo menos una década atrás. ${ }^{21}$ Fuera del control de las autoridades guatemaltecas (hasta mitad de 2009 no había presencia policiaca, o la existencia de una aduana), este cuasi-hoyo negro geopolítico es, a la vez, el único punto oficial bi-nacional en esta amplia zona de la frontera. La concomitancia de lo legal y lo no regulado hace de El Ceibo un nodo vital para la trayectoria de los migrantes en tránsito. A escala macro, de la geopolítica, puntos como El Ceibo juegan otro papel, situación que reconocen las propias autoridades mexicanas. He aquí las palabras de un funcionario del Centro de Estudios Migratorios del INM:

La importancia de la frontera sur mexicana, en la dinámica actual de la migración centro y sudamericana que transita por México hacia Estados Unidos, trasciende lo binacional con Guatemala y Belice, para convertirse en un componente estratégico regional en la relación, la cooperación y la gestión de los flujos migratorios de México y Estados Unidos. Este componente regional de la migración, no limita o subordina la transcendencia nacional del fenómeno, sino que lo coloca en un contexto más complejo de interacciones locales e internacionales [sic]. (Rodríguez Chávez, 2006: 70).

En resumen, El Ceibo es una localidad en la que frontera, seguridad y migración se intersectan en forma inequívoca por ser un punto de tránsito para bienes y personas, de manera regular e irregular. Pero si bien El Ceibo es el único punto oficial, visible, existen muchos más cruces «ciegos» a lo largo de la delimitación internacional por los cuales se desborda la migración en tránsito. Ese es el tema que me ocupa a continuación.

${ }^{20}$ Sobre el desarrollo histórico de esta comunidad véase Arriola, 2005, capítulo 5.

21 De la mercancía asiática, las armas y los migrantes existe información hemerográfica en los medios mexicanos y guatemaltecos. Véase, por ejemplo: Edición electrónica del diario Tabasco Hoy, 5 de mayo de 2007, "Decomisan tangas en las calles del Centro» http://www.tabascohoy.com/nota_interior_impresa.php?id_nota=132871, portal visitado, 11 de octubre de 2009; edición electrónica de revista Proceso, 25 de diciembre de 2006 , «Admite SSP: Tabasco sigue siendo paso de gran cantidad de droga» http://www.proceso.com.mx/noticias_articulo.php?articulo=35994, portal visitado el 12 de octubre de 2009; edición electrónica de Prensa libre, 13 de agosto de 2006, "Peligrosa ruta de migrantes» http://www.prensalibre.com/pl/2006/agosto/13/lectura_dept.html, portal visitado del 11 de octubre de 2009. 


\section{MIGRACIÓN EN TRÁNSITO}

La migración de paso, o en tránsito, tiene el carácter de ilícita debido al hecho de que estos migrantes, mayormente de origen centroamericano, se trasladan por territorio mexicano sin la documentación que exige la ley.22 Tabasco es una de las entidades del sureste mexicano en donde el fenómeno ha crecido considerablemente en los últimos tiempos. El flujo que ingresa a México vía territorio tabasqueño dio inicio hace aproximadamente tres décadas, incrementándose de manera substancial en los últimos 15 años, según se desprende de numerosas entrevistas realizadas con informantes locales. Durante este periodo, prácticamente todos los asentamientos guatemaltecos próximos a Tabasco han sido utilizados en un momento u otro como puntos de ingreso furtivo a México por parte de esta población migrante. Lo cierto es que un habitante fronterizo declaró a este autor que la fundación de una de esas comunidades estuvo directamente vinculada al negocio del tránsito de migrantes (Fulgencio Nava, pseudónimo, comunicación personal, julio 2009). El móvil principal para el tránsito de los extranjeros por este espacio fronterizo es la búsqueda del tren como medio de locomoción hacia el centro de México, el cual puede ser abordado en puntos tales como San Pedro, El Águila, El Bari (todos en Balancán), o la cabecera municipal de Tenosique, el destino preferido de gran parte de los migrantes.

No existen datos exactos sobre la cantidad de migrantes que se internan a México por estos pasos fronterizos. Es posible hacer algunas estimaciones indirectas, o como diría Rodolfo Casillas «apreciaciones» (Casillas 2008: 158), a partir de cifras generadas por diversas instancias, pero aun así la cantidad no se acercaría, ni de lejos, a las cifras reales. El Instituto Nacional de Migración mantiene un registro de las personas aseguradas en la zona que cubre la Delegación Regional, y que incluye a los municipios de Balancán y Tenosique, pero esos detenidos representan una fracción de todo el flujo; la mayoría logra eludir los controles migratorios.

Lo que si revelan distintas fuentes,$^{23}$ mis propias entrevistas y observaciones realizadas con migrantes es un perfil somero de la población en tránsito: principalmente son nacionales guatemaltecos y hondureños, mayoritariamente hombres, y casi todos jóvenes (menores de 25 años). Asimismo, he detectado un número creciente de adolescentes con ambiciones de llegar al «norte». Otro detalle que llama la atención es el hecho de que en casi todos los grupos (nunca he visto un

${ }^{22}$ No pretendo insinuar que la migración es un delito en sí mismo. El propio gobierno de México ha dado un paso muy positivo en esa dirección al derogar en 2009 el artículo en la Ley General de Población en el cual se criminalizaba y penalizaba a las personas que transgredían esta normativa por encontrarse en forma no autorizada en territorio mexicano.

${ }_{23}$ Ver, por ejemplo: Casillas, 2008; 159; Comisión de Derechos Humanos de Tabasco, 2005; Instituto Nacional de Migración, Cuadro 3.1.1., Eventos de extranjeros alojados en estaciones migratorias según país de nacionalidad, enero-octubre 2009 en http://www.inm.gob.mx/index.php?page/ Extranjeros_alojados_y_devueltos, portal visitado el 11 de noviembre de 2009 . 
migrante solitario) hay uno o dos viajeros reincidentes. Son aquellos que están intentando la travesía una vez más después de haber sido repatriados a sus países ya fuese porque fueron asegurados y expulsados de México, o porque fueron deportados desde Estados Unidos.

El paso de migrantes resulta redituable para una parte de la población local porque ese sector brinda apoyo logístico a los transeúntes en su desplazamiento, algo que sólo puede funcionar eficientemente debido a diversos niveles de complicidad y coordinación entre mexicanos y guatemaltecos residentes en la proximidad de la delimitación internacional. A ambos lados de la frontera hay los que guían, otros que sirven de mensajeros o centinelas, los que transportan, los que proveen alimentación y hospedaje para los migrantes. Los migrantes hacen uso de esos servicios en función de factores tan diversos tales como su familiaridad previa con la ruta, su conocimiento práctico del viaje, ${ }^{24}$ si contratan los servicios de un coyote, si viajan con un familiar, con amigos o en forma independiente, pero especialmente si cuentan con el dinero suficiente para movilizarse. El nivel de seguridad con que cuenta un migrante para asegurar su integridad física, la vida misma, está directamente ligado al pago que pueda ofrecer para protegerse de posibles atropellos de maleantes (organizados o no), y/o abuso de elementos corruptos de los cuerpos de control del estado. Los migrantes que no cuentan con recursos económicos deben caminar cientos de kilómetros para poder alcanzar su objetivo, sufriendo penalidades y vejaciones; ${ }^{25}$ quienes si cuentan con dinero son trasladados, resguardados y alimentados a través de redes nacionales y transfronterizas. No sorprende, por consiguiente, que las medidas de políticas de seguridad estadocéntrica (de patrullaje, control, restricción) se hagan sentir con mayor fuerza en el primer grupo y, por lo general, mucho menos en el segundo. En tiempo reciente surgió otro elemento que hizo mucho más complicada la situación de los migrantes en tránsito por la zona de Tenosique, y por ende el tema de seguridad: la participación de los Zetas en el secuestro y extorsión de migrantes (Comisión Nacional de los Derechos Humanos 2009, Martínez, 2009).

Bajo las condiciones arriba descritas los transmigrantes no representan peligro alguno para la seguridad convencional del país, es decir una amenaza a la seguridad pública. La presencia y enraizamiento de cuerpos delictivos como los auténticos y supuestos Zetas que operan en la zona de estudio, sí representan un peligro mayor para la seguridad de la sociedad en su conjunto. A continuación

\footnotetext{
${ }^{24} \mathrm{El}$ migrante extranjero que conoce el trayecto a seguir, que maneja ciertas claves culturales (manifestado de manera muy diversa a través de detalles como el gusto por el picante, identificar los nombres de las cervezas más populares, utilizar los vocablos del lenguaje vernáculo y popular, e imitar ciertos acentos locales) tiene más probabilidades de cruzar exitosamente territorio mexicano, a diferencia de aquel que transita por vez primera en este país sin contar con ese "capital» cultural.

${ }^{25}$ Las distintas situaciones por las que atraviesan los sujetos que están involucrados en el contrabando de humanos (secuestros, torturas, persecución, corrupción, discriminación...) hacen que el tema adquiera múltiples aristas que conciernen a la relación seguridad humana-derechos humanos (ver por ejemplo, Benedek, 2008; Kyle y Koslowsky, 2001a).
} 
discutiré por qué considero que en el tratamiento del fenómeno migratorio, en particular, es necesario entreverar las nociones estado-céntrica y humana de seguridad, una conjunción no exenta de tensiones potenciales, y por qué es difícil para el estado mediar y mantener una postura equilibrada en el tratamiento del tema migración como un asunto de seguridad en este espacio territorial.

\section{COMENTARIOS FINALES}

Las fuerzas del capitalismo clandestino (Kyle y Koslowsky, 2001b), en todas sus formas y dimensiones, se cuelan por las grietas donde el estado tiene poca o nula presencia, o a donde es incapaz de llegar con fuerza. Por ello, aquellas fronteras internacionales con escasos controles y de alta porosidad presentan las mejores condiciones para el crecimiento de cualquier actividad ilícita, entre ellas la migración no regulada. Esta situación plantea espinosas disyuntivas para la seguridad humana y la seguridad estatal.

Las actividades subterráneas que acontecen en la frontera Tabasco-Petén requieren de una respuesta adecuada y multilateral. Con esto quiero decir que el alcance de esa respuesta debe ser diseñada tomando en cuenta la perspectiva de seguridad humana porque en el momento actual el flujo de centroamericanos y otros extranjeros que transitan por este espacio fronterizo no constituyen amenaza alguna para México. Casi todos esos migrantes se encuentran en el país de manera transitoria. No ignoro que una mínima proporción se empleen temporalmente, que otros decidan residir en el país o que dentro de los grupos en tránsito haya presencia de miembros de las llamadas maras. Pero sería tendencioso e irresponsable afirmar que la mayoría de esos migrantes quitan trabajos a los mexicanos, vengan con la intención de quedarse en forma permanente, o que se dediquen a delinquir. Muy por el contrario, un alto porcentaje de los transmigrantes son víctimas de su condición o estatus, quedando a merced de autoridades y civiles inescrupulosos. Además, está presente en amplios sectores del imaginario popular una estigmatización de los migrantes irregulares, misma que puede rayar en la xenofobia, algo que, a su vez, hace más delicado para la sociedad en general, lidiar con la migración «securitizada». ${ }^{26}$

\footnotetext{
${ }^{26}$ Maggie Ibrahim sostiene que la securitización es un discurso de poder en el cual los migrantes son representados como una amenaza para el mundo liberal de las democracias occidentales (Ibrahim, 2005: 163). Para ella el enfoque de seguridad humana aumenta el riesgo hacia los migrantes, no los ayuda; su posición es bastante crítica, como deja entrever el siguiente párrafo:

Categorizar a la migración como una amenaza a la seguridad humana, junto con otras amenazas como el narcotráfico, es inquietante. En términos del fenómeno migratorio, los migrantes que cruzan fronteras para escapar guerras, persecución y hambre constituyen las poblaciones en riesgo. No obstante, debido a esta nueva aproximación humano-céntrica se percibe a los propios migrantes como amenazantes para las poblaciones del país receptor... En lugar de enfocarse en cómo apoyar a los migrantes en riesgo, el nuevo paradigma incrementa su vulnerabilidad... (169) (Traducción libre).
} 
El estado debe establecer un balance entre acciones convencionales de seguridad desde a un enfoque integral, en particular con pertinencia socio-cultural. De esa forma el propio estado puede contribuir a transformar lo que concibe como amenazas y/o peligros latentes en riesgos manejables. Quizás por ahora no sea viable erradicar o controlar totalmente las actividades irregulares existentes en la frontera sur pero sí es posible poner en marcha una agenda más abierta en términos del abordaje de estos problemas. En relación al tema migratorio vale la pena retomar la idea de "gobernabilidad migratoria democrática» sugerida recientemente por Villafuerte y García (2007: 34). Aunque los autores no precisan ni desarrollan el término creo que éste podría abarcar las siguientes consideraciones:

1) Abordar la seguridad multidimensional de forma consensuada entre gobiernos y poblaciones fronterizas y con particular atención a los aspectos sociales, económicos, políticos y jurídicos vinculados a la migración -una política no necesariamente afín a los intereses de su contraparte estadounidense-. Asimismo, dicha política multilateral deberá cuidar su potencial alcance trinacional, en este caso con Honduras o con Belice.

2) Implementar estrategias coordinadas pero diferenciadas (Castillo, 2005) al interior de México para atender los problemas que están vinculados a la migración irregular, particularmente en las zonas fronterizas binacionales de intenso contacto; dichas estrategias serán diseñadas acorde a las especificidades locales, es decir, atendiendo a las características y el contexto de la realidad socio-económica en la delimitación internacional.

3) Emprender más y mejores acciones para humanizar la violación a los derechos humanos de los migrantes en tránsito, problema muy arraigado actualmente y que empaña la trayectoria humanitaria de México en lo relativo al trato ofrecido a los migrantes.

Este llamado adquiere especial urgencia para aquellos territorios y espacios rurales que cobran mayor proyección en el contexto de la mundialización vía los procesos migratorios. Estas localidades de y con influencia global son objeto del devenir de fuerzas y vaivenes internos y externos, de dinámicas que trascienden, pero que a su vez inducen, cambios más allá de lo local-regional. El movimiento de bienes lícitos e ilícitos y de seres humanos en los linderos de Tabasco y Petén impulsa esas transformaciones, "problemas» para los cuales el paradigma vigente de seguridad es restringido y desactualizado.

\section{REFERENCIAS}

Anderson, Michael (1996), Frontiers: Territory and State Formation in the Modern World, Cambridge, Reino Unido, Polity Press.

Andreas, Peter (2003), «Redrawing the Line: Borders and Security in the Twenty-first Century", International Security, 28 (2), pp. 78-111. 
Arriola, Luis A. (2005), «Agency at the Frontier and the Building of Territoriality in the Naranjo-Ceibo Corridor, Petén, Guatemala», Tesis inédita de doctorado, antropología, University of Florida, Gainesville, Florida, Estados Unidos.

Artola, Juan (2006), «Migración y seguridad, México y la frontera norte», en Carlos Miranda V., Ernesto Rodríguez Ch., Juan Artola (coords.), Los nuevos rostos de la migración en el mundo, compilación de trabajos presentados en el foro internacional de las migraciones, Gobierno del Estado de Chiapas, oIm, INM, Tuxtla Gutiérrez, Chiapas, pp. 99-112.

Bellamy, Alex J. y Matt McDonald (2002), "The Utility of Human Security” Which Humans? What Security? A Reply to Thomas \& Tow», Security Dialogue, 33 (3): 373377.

BENEDEK, Wolfang (2008), "Human security and human rights interaction», International Social Science Journal, 59: 1, pp. 7-17, septiembre.

Benítez M., Raúl (2009), «La nueva seguridad regional: Amenazas irregulares, crimen organizado y narcotráfico en México y América Central», comentario, Fundación para las Relaciones Internacionales y el Diálogo Exterior, España, 5p. Disponible en el portal www.fride.org. Consultado el 6 de noviembre, 2009.

Buzan, Barry, Ole Waever y Jaap de Wilde (1998), Security: A New Framework for Analysis, Lynne Rienner, Colorado, Boulder.

Cameron, Fraser (2006), «Transcultural Issues, Globalization, and Global Security», Geneva Centre for Security Policy (GCSP), Policy Brief Series, núm. 2., 10 p., junio.

Casillas R., Rodolfo (2008), "Las rutas de los centroamericanos por México, un ejercicio de caracterización, actores principales y complejidades», Migración y Desarrollo, 10, primer semestre, pp. 157-174.

Castillo, Manuel A. (2005), «Fronteras, Migración y Seguridad en México», Alteridades 15, 030, pp. 51-60, jul-dic.

(2002), «Región y Frontera: La frontera sur de México», en Edith F. Kauffer M. (ed.), Identidades, migraciones y género en la frontera sur de México, México, El Colegio de la Frontera Sur, Chiapas, pp. 19-48.

, Mónica Toussaint R. y Mario Vázquez O. (2006), Espacios Diversos, historia en común, Secretaría de Relaciones Exteriores, Colección las Fronteras de México, México.

Comisión de Derechos Humanos (México) (2009), «Informe Especial de la Comisión Nacional de los Derechos Humanos sobre los casos de secuestro en contra de migrantes», México, Distrito Federal, 53 p.

Comisión de Derechos Humanos de TABAsco (2005), «La transmigración centroamericana por el estado de Tabasco», Informe de investigación, s.n.p., disponible en http://www. codehutab.org.mx/librotransmigrante.html, portal visitado el 3 de septiembre, 2009.

DAVIES, Sara E. (2008), «Securitizing infectious disease», International Affairs, 84: 2, pp. 295-313.

De Genova, Nicholas (2002), "Migrant 'Illegality' and Deportability in Everyday Life», Annual Review of Anthropology, 31: 419-447.

De Vos, Jan (2005), «La Formación de la frontera entre México y Centroamérica», en Salvador Hernández D. (coord.), Frontera Sur de México: cinco formas de interacción entre sociedad y ambiente, México, El Colegio de la Frontera Sur, Chiapas, pp. 15-20. 
(1993), Las Fronteras de la Frontera Sur: Reseña de los proyectos de expansión que figuraron la frontera entre México y Centroamérica, México, Universidad Autónoma Juárez de Tabasco/Centro de Investigaciones y Estudios Superiores en Antropología Social, Villahermosa, Tabasco.

Dillon, Michael (2005), «Global Security in the $21^{\text {st }}$ Century: Circulation, Complexity and Contingency», World Today, 61, pp. 2-3, suplemento, noviembre

Ewan, Pauline (2007), «Deepening the Human Security Debate: Beyond the Politics of Conceptual Clarification", Politics, 27: 3, pp. 182-189.

Friman, H. Richard y Peter Andreas (1999), The Illicit Global Economy and State Power, Rowman and Littlefield Publishers, Maryland, Lanham.

Heyman, Josiah (ed.) (1999), States and Illegal Practices, Berg, Oxford y Nueva York.

y Alan Smart (1999), «States and Illegal Practices: An overview», en Josiah Heyman (ed.), States and Illegal Practices, Oxford y Nueva York, Berg, pp. 1-24.

IBRAHIM, Maggie (2005), «The Securitization of Migration: a Racial Discourse», International Migration, 43: 5, pp. 163-187.

Kyle, David y Rey Koslowsky (2001a), "Introduction», en David Kyle y Rey Koslowsky (eds.), Global Human Smuggling: Comparative Perspectives, Baltimore y Londres, The Johns Hopkins University Press, pp. 1-25.

(2001b), «Smuggling the State Back In: Agents of Human Smuggling Reconsidered», en D. Kyle y R. Koslowsky (eds.), Global Human Smuggling: Comparative Perspectives, Baltimore y Londres, The Johns Hopkins University Press, pp. 29-57.

LiotTA, Peter H. (2002), «Boomerang Effect: the Convergence of National and Human Security», Security Dialogue, 33: 4, pp. 473-488.

Martínez, Óscar. (2009), «Nosotros somos los Zetas», El Faro (periódico digital), Sección Migración, Nota del 24 de agosto, 2009 http://www.elfaro.net/secciones/migracion/ default.php?nota=noticias032_1, Consultado el 2 de septiembre de 2009.

McCormack, Tara (2008), "Power and Agency in the Human Security Framework», Cambridge Review of International Affairs, 21: 1, pp. 113-128.

NAím, Moisés (2005), Illicit: How Smugglers, Traffickers, and Copycats are Hijacking the Global Economy, Nueva York, Anchor Books.

Navaro-Yashin, Yael (2003), "Life is dead here': Sensing the Political in no man's land", Anthropological Theory, 3: 1, pp. 107-125.

Nef, Jorge (1999), Human Security and Mutual Vulnerability: the Global Political Economy of Development and Underdevelopment, 2da. ed., Ottawa, International Development Research Centre.

(1995), «Gobernabilidad, capacidad de gobierno y seguridad humana: un marco de referencia para el estudio comparativo de las políticas de ajuste estructural en América Latina", ponencia presentada en la conferencia dictada en el Primer Seminario-Taller sobre Impacto del Cambiante Contexto Internacional sobre los países de la cuenca del Caribe celebrada en Tlaxcala, México, en mayo de 1992, título original: Gobernability, Governance and Human Security, Trad. Rubén Nájera, Serie Textos para el Debate, núm. 7, Asociación para el Avance de las Ciencias Sociales en Guatemala, Guatemala.

(1991), "Democratization, Stability and other Illusions: Militarism, Nationalism and Populism in the Political Evolution of Latin America with Special Reference to 
the Chilean Case», en Mark Dickerson y Stephen Randall (eds.), Canada and Latin America: Issues of the year 2000 and Beyond, Calgary, The International Centre, University of Calgary, pp. 73-122.

Nordstrom, Carolyn (2001), "Out of the Shadows», en Thomas Callaghy, Ronald Kassimir, and Robert Latham (eds.), Intervention and Transnationalism in Africa: Global-local Networks of Power, Cambridge, Cambridge University Press, pp. 216-239.

Rodríguez BerufF, Jorge (2006), «La guerra contra las drogas y los orígenes caribeños del concepto de seguridad multidimensional», en Joseph Tulchin, Raúl Benítez M. y Rut Diamint (eds.), El rompecabezas, conformando la seguridad hemisférica en el siglo XXI, Buenos Aires, Prometeo Libros y Bononiae Libris, pp. 321-30.

Rodríguez ChÁvez, Ernesto (2006), «Frontera sur y política migratoria en México (circularidad, seguridad y derechos humanos)», Foreign Affairs en Español, 6: 4, pp. 64-70.

Ryerson, Christie R. (2008), "The human security dilemma: Lost Opportunities, Appropriate Concepts, or Actual Change?», en Peter H. Liotta, David A. Mouat, William G. Kepner, Judith M. Lancaster (eds.), Environmental Change and Human Security: Recognizing and Acting on Hazard Impacts, Países Bajos, NATO Science for Peace and Security Series C- Environmental Security, Springer, pp. 253-269.

Schendel, Willem van e Itty Abraham (eds.) (2005), Illicit Flows and Criminal Things: States, Borders and the Other Side of Globalization, Indiana, Indiana University Press, Bloomington.

Schwartz, Norman (1990), Forest Society: A Social History of Peten, Guatemala, Philadelphia, University of Pennsylvania Press.

StaUdT, Kathleeen (1998), Free Trade: Informal economies at the US-Mexico Border, Philadelphia, Temple University Press.

TulCHin, Joseph S. (2005), «Creando una comunidad de seguridad en el hemisferio», Nueva Sociedad, 198, julio-agosto, pp. 102-126.

un, Development Program (1994), «New Dimensions of Human Security», Informe sobre Desarrollo Humano, disponible en http://hdr.undp.org/en/reports/global/hdr1994/ chapters/, Consultado el 10 de octubre, 2009.

VARGAS, Patricia (1993), Los Embera y los Cuna: Impacto y reacción ante la ocupación española, siglos XVI y XVII, Bogotá, Colombia, Instituto Colombiano de Antropología.

Villafuerte Solís, Daniel y María del Carmen García Aguilar (2007), «La doble mirada de la migración en la frontera sur de México: asunto de seguridad nacional y palanca del desarrollo», Revista LiminaR, Estudios Sociales y Humanísticos, V: 2, diciembre, pp. 26-46.

WiLson, Thomas M., y Hastings Donnan (1998), «Nations, State and Identity at International Borders», en Thomas Wilson and Hastings Donnan (eds.), Border Identities: Nation and State at International Frontiers, Cambridge y Nueva York, Cambridge University Press, pp. 1-30. 